work which carried out with the more recently developed technique, is at the same time accurate and of importance in clinical medicine.

The first chapter deals with general considerations of the acid-base balance of the blood, alkali reserve, etc., and the second chapter takes up the question of the normal $\mathrm{pH}$ values. In the third chapter, the question of the $\mathrm{pH}$ value of the plasma in various diseases is discussed. The findings in the various diseases, as recorded, are more of academic interest than of practical value to the practitioner. The last chapter is concerned with the various methods of determination of $\mathrm{pH}$ values.

There is a most complete list of references and a carefully arranged index.

It is a book which would make a more valuable addition to the library of a biochemical laboratory than the shelves of the practising physician.

\section{C. Montgomeri}

Advice to the Expectant Mother on the Care of Her Health. F. J. Browne, M.D., D.Sc., F.R.C.S.E., Professor of Obstetric Medicine in the University of London, and Director of the Obstetrical Unit at University College Hospital, London. 40 pages. Price 6d net. F. \& S. Livingstone, 16 and 17 Teviot Place, Edinburgh, 1926.

This short treatise on antenatal care is written not to replace personal interviews with a physician, but to emphasize the importance of such care. It also givies the mother the details to study at leisure, which might easily be overlooked or forgotten during an office visit.

The various signs of pregnancy, symptoms of oncoming labour, the duration of pregnancy are all discussed. Suitable treatmen't is suggested for the minor disorders of pregnancy, such as constipation, nausea, cramps, sleeplessness, hæmorrhoids, etc. As danger signals, hæmorrhage, marked œdema, persistent headache, scanty urine, and severe vomiting are cited.

The patient is urged to notify the obstetrician at once should any of these occur. The last chapter deals with the baby, how and when it should be nursed and the care of the nipples.

In simple language, the author concisely answers many of the questions which would arise in the mind of the expectant mother and also gives her warning of symptoms which, if neglected, might lead to serious trouble. Eleanor Perctval

Tuberculosis: Its Prevention and Treatment. John Laird. 130 pages. Price $\$ 1.65$. John Wright \& Sons Ltd., Bristol. The Macmillan Co., Toronto, 1926.

The opening sentence of this book reveals its true form, thus "The calcium salts must claim our first and very special consideration, as all our efforts to combat tuberculosis without their aid will end in disappointment and failure." For the greater part, the author deals with the use of calcium and other drugs in tuberculosis. There is also an appendix containing some "thoughts and reasonings" on the prevention and cure of various disorders by the administration of the salts of calcium and potassium. It is a hodge-podge of medical superstitions which might have made interesting reading half a century ago, but not to-day.

KEITH GORDON

Bainbridge and Menzies Essentials of Physiology. Fifth edition. Edited and revised by C. Lovatt Fvans, D.Sc., M.R.C.S., L.R.C.P., F.R.S. 508 pages, illustrated. Price $\$ 5.00$. Longmans, Green and Co., 210 Victoria St., Toronto, 1926.

This book has always appealed strongly to the medical student for whom definitely it is intended. It may be that, compared with its competitors, its re- stricted size has made this appeal, but if so the student has been fortuitously led to a sound selection of a companion book. In form it is ill adapted for the casual or indifferent student, nor is it intended to provide for the belated acquisition of an examination standing.

Even though all superfluous and much of the cognate matter found in discoursive text-books have been omitted so that the title "Essentials" might be realized, the lethargic student will find the sustained sequence of concentrated and compressed fact rather a heavy burden. On the other hand in these very features lies its value to the conscientious student. In conjunction with the lecture and laboratory courses now in vogue he will read it with pleasure and advantage. It is to our mind an exceedingly clearly written, well constructed and suggestive survey of the subject. The designation "Essentials", though rather a daring one, is perhaps, the title most appropriate to the actual form and purpose of the book; at least it can be said on the one side that there is practically nothing in it that is not essential.

The whole plan, printing and illustration of the book is attractive, and as has been suggested the dissertation is precise, definite and free from difficulty of interpretation. Both the original authors are now dead, and for the present edition Professor Lovatt Evans is responsible. He disclaims any extensive alteration in the text, and, in fact, it would be well for its purpose if the book were maintained much as it is without any serious disturbance of design.

G. SPENCER MELVIN

Transactions of the American Surgical Association. Vol. 43. Edited by John H. Jopson, M.D. 986 pages, illustrated. William J. Dornan, Philadelphia, 1925

This volume is a compilation of papers and addresses by Fellows of the Association. The discussion on the various papers are also recorded. The book as a whole should appeal to the surgical specialist, for in it he will find articles putting forth ideas on diagnosis and surgical technique, which have been tried and proven, and are well past the experimental stage. The authors are men of outstanding ability and experience, coming from the various teaching centres of Canada and the United States.

A few of the subjects dealt with may be mentioned: Sequelæ of gastro-enterostomy, by Balfour; Carcinoma of the body of the uterus, by Davis; Repair of injuries to the posterior crucial ligament of the knee, by Gallie and Le Mesurier; Relation of the spleen to chronic purpura, by Mayo; Splenectomy in thrombopenic purpura, by Vincent. The volume is completed with a lengthy article on End-results in periosteal sarcoma in long bones by William B. and Bradley L. Coley.

All the articles in the volume are well written and concise and make very enjoyable reading.

The printing, quality of paper, and binding are in keeping with the quality of the contents.

R. V. B. SHIER

Pernicious Anæmia. Frank A. Evans, M.D. 178 pages. Price \$2.50. The Williams \& Wilkins Company, 1926.

This book is a clinical study of pernicious anæmia, written for the guidance of the general practitioner. It includes a good description of the signs and symptoms of the disease, the differential diagnosis, and a discussion of the etiology, prognosis, and treatment. Statistical deductions are largely based on a series of 111 cases of the disease, from the records of the Johns Hopkins Hospital.

A considerable space is devoted to the possible etiology of the disease. Many of the views regarding 